\title{
Antes y después del centro cultural: renovación urbana y desplazamiento en Bogotá
}

\author{
Before and after Cultural Center: \\ Urban Recovery and Displacement in Bogotá
}

\author{
Diana Carolina Urbina Vanegas \\ Antropología Social \\ Universidad de Buenos Aires \\ carolinaurbinav@gmail.com
}

\begin{abstract}
$\overline{\text { RESUMEN }}$
En el presente artículo, revisaré los efectos que han tenido las políticas de renovación urbana en el centro histórico de Bogotá, retomando la experiencia de los antiguos habitantes de la Manzana 5, ubicada en el barrio Las Aguas. En primer lugar, presentaré un análisis crítico del discurso en el que se posiciona la renovación urbana y del lugar estratégico que ocupa el deterioro del centro histórico. En la segunda parte, me acercaré a los residuos que deja a su paso un proceso de renovación que no contempla el factor social: las ruinas y el desplazamiento urbano, un fenómeno que se fundamenta en estrategias legítimas e ilegítimas de ordenamiento territorial.
\end{abstract}

Palabras clave: ciudad, renovación urbana, desplazamiento urbano.

\begin{abstract}
$\overline{\text { ABSTRACT }}$
In this article, I will revise the effects of the urban renewal politics in the historical center of Bogotá, taking into account the experience of the former inhabitants of Manzana 5, located at Las Aguas neighborhood. In the first place, I will present a critical analysis of the discourse in which urban renewal takes place, and the strategic place of the historical center deterioration. In the second part, I will approach to the wastes generated by a renewal process that does not recognize the social factor: the ruins and urban displacement, a phenomenon that is based on legitimate and illegitimate strategies of territorial order.
\end{abstract}

Keywords: city, urban renewal, urban displacement. 


\section{Introducción ${ }^{1}$}

Al realizar un breve recorrido histórico, se observa que las transformaciones urbanas llevadas a cabo en el centro de Bogotá se han caracterizado por estar al margen de los intereses locales. A finales del siglo XIX y comienzos del XX, la ciudad experimentó rápidas transformaciones que respondían a la ruptura con el orden colonial y a la formación del estado nacional. Cabe destacar que tanto el orden urbano colonial como el republicano fueron comandados por las élites gobernantes que lograron obtener legitimidad por medio de la construcción de escenarios de poder. Primero, la plaza y las estructuras religiosas; luego, la expansión del centro, la formación de zonas financieras, administrativas, comerciales y culturales asociadas a los grupos de mayores ingresos. Esta situación se fortaleció con el poco interés de los habitantes en la construcción de los asuntos públicos, proveniente principalmente del estrecho vínculo con el espacio privado, todavía custodiado por fuertes mandatos religiosos (Mejía 2000).

Estos son los fundamentos del proyecto modernizador que vive la ciudad a mediados del siglo XX, que se caracteriza por la implementación de programas sociales, económicos y políticos basados en el discurso del progreso proveniente de Estados Unidos y de los países europeos. Las transformaciones en la infraestructura de la ciudad no se hicieron esperar, pero no puede decirse lo mismo de la crisis que estaba viviendo el país a causa de la "violencia rural, la migración masiva de campesinos a las ciudades y las rupturas consecuentes en las estructuras económicas y culturales existentes” (Saldarriaga 2000, 20-21).

De cara al siglo XXI, las políticas que le apuestan al ordenamiento del territorio continúan, en gran parte, dejando de lado a los habitantes de las zonas centrales y de aquellas en proceso de renovación. Thierry Lulle (2008) resalta que la caracterización que se hace de la población en el Plan Zonal del Centro (Decreto 492 de 2007) tiende a ser engañosamente homogénea. Los pobladores de esta zona de la ciudad no se diferencian de los habitantes de otras necesariamente por las condiciones de pobreza; se pueden encontrar diversas actividades económicas y un fuerte anclaje al territorio. En todo caso, el imaginario sobre la

1 Este artículo corresponde al trabajo de campo realizado durante el 2013, en el marco de la beca "Apoyos para investigaciones en antropología social: nuevas perspectivas de la antropología colombiana", otorgada por el Instituto Colombiano de Antropología e Historia (ICANH). Adicionalmente, el trabajo se inscribió en la categoría Pioneros de la Antropología: Roberto Pineda Giraldo. Se trata de un proyecto realizado como parte de mi tesis de maestría en Antropología Social de la Universidad de Buenos Aires, dirigida por la Dra. en antropología Virginia Manzano. Agradezco los comentarios de Juana Camacho Segura y la lectura del texto hecha por María Teresa Salcedo. 
ciudad incluido en dicho plan apoya la renovación de actividades económicas y de la población, lo que conduce directamente al beneficio de grupos con mayores ingresos, más acordes con los modos de vida que se desean visibilizar en esta zona.

A partir del estudio realizado con diferentes actores involucrados en el Plan Zonal del Centro, Vargas (2011) presenta una crítica al proceso participativo. El plan se ha caracterizado por "generar consensos a partir de disensos", con el único fin de cumplir con la renovación urbana, dejando de lado los intereses de la comunidad. Las organizaciones sociales del centro resaltaban problemáticas de fondo, tales como "el modelo político y económico del país, los desplazamientos de los habitantes tradicionales y las dinámicas expansionistas de las universidades” (97-98), que no fueron consideradas. Aquellos sectores que no se vieron representados se retiraron del proceso y, aun así, "las firmas de asistencia al conjunto de todos estos eventos sirvieron como soporte aprobatorio del componente social y comunitario del Plan Zonal del Centro de Bogotá” (98).

Para explorar esta tensión entre los intereses locales y gubernamentales, me he centrado en el proyecto Centro Cultural Español y en las prácticas políticas y jurídicas desarrolladas por los habitantes del sector de Las Aguas, específicamente de la Manzana 5, para enfrentar el desplazamiento².

En 2006, la Empresa de Renovación Urbana (ERU) y la Agencia Española de Cooperación Internacional (AECI) firmaron un convenio para construir un Centro Cultural Español en la Manzana 5 del barrio Las Aguas y, junto a este, un proyecto comercial y de vivienda para atraer nuevos residentes al sector. La ERU compró los terrenos, adquirió la licencia de construcción, expropió a los habitantes y demolió los inmuebles. Por su parte, el gobierno español, en cabeza de la AECI, estaba encargado de construir y de administrar el centro cultural por un periodo de 65 años (Contraloría 2011a). Sin embargo, esta institución no cumplió con el compromiso pactado. Las obras se retrasaron y ello generó malestar en los propietarios y el gobierno nacional. En 2012, la AECI terminó el convenio, devolvió el predio y, en 2013, rembolsó el dinero correspondiente a la licencia de construcción (“España reembolsó” 2013).

El terreno contaba en total con 24 predios; el 86,83\% pertenecían al sector privado y el $13,17 \%$, al sector público, según un documento técnico de la ERU (2006). No obstante, en un informe realizado por la Contraloría (2011b),

2 Dado que me he concentrado en estudiar el desplazamiento y no la gentrificación, me referiré a las consecuencias que ha dejado la renovación del sector desde la mirada de los afectados y no a lo que ocurre con los grupos de mayores ingresos ni al proceso de ocupación del centro por grupos poblacionales de clase media y alta. 
se establece que la ERU adquirió, en total, 37 predios por medio de la figura de enajenación voluntaria y, dada la objeción de algunos propietarios, 13 de estos predios se adquirieron por medio de la expropiación administrativa. La ERU contrató a la Lonja de Propiedad Raíz de Bogotá para realizar los avalúos, que se obtuvieron por medio de una metodología de comparación en la que se utilizaron predios ubicados en sectores como Las Cruces y Santa Fe, que no contaban con características similares a los inmuebles ubicados en la Manzana 5. La ERU omitió el procedimiento de verificar y solicitar la investigación de mercado que sustentaba dicho estudio; por esta razón, los avalúos realizados de forma inconsistente se consideraron vigentes durante la adquisición de la mayoría de los predios. Algunos propietarios demandaron este hecho, ya que terminarían recibiendo un monto sumamente bajo para un predio ubicado en el centro histórico. De acuerdo con el informe, una vez hecho el segundo avalúo, se incrementó el precio de 12 inmuebles.

Los habitantes que fueron expropiados no recibieron la suma correspondiente de forma inmediata. El dinero fue enviado al Tribunal Administrativo de Cundinamarca, específicamente a la Sección Primera, y en esa cuenta permaneció por más de un año. Nuevamente, la Empresa de Renovación Urbana cometió un error en el trámite, porque en lugar de eso debió haber retirado el dinero para consignarlo directamente a los propietarios (A. Sanabria y S. Suárez, comunicación personal) ${ }^{3}$. Eso ocurrió en el 2008, pero los procedimientos no se realizaron correctamente y todavía en el 2013 algunos habitantes no habían recibido el pago por sus propiedades. Finalmente, en el 2014 se conoció el nuevo nombre del proyecto: Núcleo Educativo y Cultural Las Aguas. De acuerdo con la Alcaldía Mayor de Bogotá, "la nueva Cinemateca Distrital, el proyecto residencial estudiantil City U y el Plan Parcial Progresa Fenicia” entrarán a ocupar la Manzana 5, un espacio de $7.803 \mathrm{~m}^{2}(2014,25)$.

La investigación de la que se ocupa este texto inicia en el 2013, cuando el terreno se encontraba prácticamente desocupado y solo quedaban dos casas. Hasta el momento, he podido establecer contacto con dos familias que fueron expropiadas y con un habitante que tenía ubicado allí su establecimiento comercial. La información sobre otros residentes ha sido difícil de obtener, ya que los habitantes afirman que se encuentran en zonas alejadas de la ciudad y no cuentan con sus datos de contacto. En la primera parte del presente artículo realizo

3 Estos datos hacen parte del discurso emitido por el abogado de uno de los habitantes, en la Comisión Primera de la Cámara de Representantes, en 2010. La grabación de esta audiencia fue consultada durante la entrevista realizada por la investigadora a los antiguos residentes. 
una aproximación al contexto de la renovación urbana y enseguida exploro el concepto de deterioro en el centro histórico. En la tercera parte recurro a las ruinas para hablar de las personas que fueron desplazadas de la Manzana 5, y finalmente menciono las estrategias legítimas e ilegítimas a través de las cuales se ordena el territorio.

\section{El contexto de la renovación urbana}

Siguiendo el recorrido trazado hasta el momento, que permite ver las disputas territoriales que se han dado entre una diversidad de actores estatales y privados, surge la pregunta por la legitimidad de los procesos de renovación y, más específicamente, por la relación que estos proyectos puedan tener con el desplazamiento de los habitantes ¿Será que, efectivamente, la ley construida para ordenar el territorio en la ciudad está avalando, ya sea de forma directa o indirecta, la expulsión de los habitantes del centro?

Las políticas son textos llenos de significados culturales y simbólicos (Oszlak y O’Donnell 1982; Pérez 2010; Ramírez 2010; Shore 2010; Wincour 1996), en los que se reúnen nociones concretas sobre el espacio y los sujetos. Para evitar una posición de enfrentamiento entre el estado y la población, resalto la complejidad de los programas estatales y la disputa entre agentes globales, nacionales, locales y populares.

El marco jurídico que rige la construcción territorial en Colombia comienza a formarse con la Ley 9 de 1989, de reforma urbana (Secretaría General de la Alcaldía Mayor de Bogotá 1989). Basada en técnicas modernas de planeación urbana, esta ley establece que los terrenos no urbanizados deben desarrollarse en función de criterios de conservación, redesarrollo y rehabilitación. El espacio público queda constituido por aquellos inmuebles asociados al bienestar colectivo, de modo que se toma una distancia definitiva de cualquier interés individual. Se habla incluso de acciones populares para la defensa del espacio público. Lo público, o la noción asociada a este, adquiere un estatus privilegiado cuando se trata de proyectos de renovación urbana. El gobierno puede apelar a la enajenación voluntaria y a la expropiación únicamente con el objetivo de desarrollar proyectos de utilidad pública o de interés social ${ }^{4}$. Finalmente, cabe destacar que

4 En la enajenación voluntaria, el propietario acepta la oferta de compra por parte de la entidad pública. Si la rechaza, puede acudir a la expropiación judicial. A los doce meses de decretar la expropiación por parte de un juez, el dueño debe desocupar el predio y esperar 
esta ley protege a los moradores que puedan verse afectados por proyectos de renovación. Los habitantes propietarios deben quedar ubicados en el mismo sitio cuando se trate de un proyecto de vivienda y aquellos que no cuentan con esa condición deben quedar reubicados cerca al lugar donde vivían.

Con la expedición de la Ley Nacional 388, del año $1997^{5}$ (Secretaría General de la Alcaldía Mayor de Bogotá 1997), se establecen los criterios de los planes de ordenamiento territorial, enfocados en la conservación del medio ambiente y del patrimonio cultural, histórico, artístico y arquitectónico. La participación democrática es central, pues se deben integrar los intereses sociales, económicos y urbanísticos. Los planes de ordenamiento territorial se desarrollan a través de unidades de actuación urbanística (UAU) ${ }^{6}$, para garantizar el uso racional del suelo, el cumplimiento de la norma y para repartir equitativamente los cargos de infraestructura vial, servicios públicos domiciliarios y equipamientos colectivos (art. 39). Si bien las UAU son un instrumento de gestión del suelo que facilita la ejecución, la participación de los habitantes muchas veces se limita a aceptar la inclusión de su predio dentro del área y, una vez alcanzado el aval del $51 \%$, se aplica la figura de expropiación a los demás habitantes (Mayorga 2012).

Más adelante, el Distrito crea la Empresa de Renovación Urbana (ERU), asociada a la Secretaría de Hábitat, cuyas facultades se definen del siguente modo:

[la] recuperación y transformación de sectores deteriorados del suelo urbano, mediante programas de renovación y redesarrollo urbano, [...] el desarrollo de proyectos estratégicos en suelo urbano y de expansión con el fin de mejorar la competitividad de la ciudad y la calidad de vida de sus habitantes. (Acuerdo 33 de 1999)

Actualmente, la ERU se encuentra ejecutando el proyecto Núcleo Empresarial Estación Central, en la zona de Santa Fe y Mártires, el Núcleo Educativo y Cultural Las Aguas y el Núcleo Comercial San Victorino ${ }^{7}$, tres zonas que integran el plan de ordenamiento para el centro de la ciudad.

entre tres y ocho años para recibir el precio indemnizatorio. Si elige la expropiación por vía administrativa, inicialmente se consigna el dinero y posteriormente los propietarios tienen la opción de debatir el pago recibido (Instituto de Estudios Urbanos 2011b).

5

6

7
Esta ley se modificó en el 2003, a través de la Ley 810.

"Área conformada por uno o varios inmuebles, explícitamente delimitada en las normas que desarrolla el plan de ordenamiento que debe ser urbanizada o construida como una unidad de planeamiento" (Ley 388 de 1997, art. 39).

Este proyecto ha presentado irregularidades en la ejecución. La Contraloría elaboró un informe en el que advierte el riesgo de detrimento patrimonial que existe, debido a los 
En el año 2000, a través del Decreto 619 (Secretaría General de la Alcaldía Mayor de Bogotá 2000), se adopta por primera vez el Plan de Ordenamiento Territorial (POT) del Distrito. Tal como se establece en el Decreto 190 de 20048, uno de sus objetivos es "procurar la utilización racional del suelo para favorecer el interés común, la sostenibilidad ambiental y la preservación del patrimonio” (Secretaría General de la Alcaldía Mayor de Bogotá 2004). Dicha intención se relaciona con el rápido proceso de urbanización que ha vivido la ciudad. Según la Alcaldía Mayor de Bogotá (2013), el desequilibrio territorial se manifiesta en la existencia de una periferia sobrepoblada y de una zona céntrica con poca población residente, lo que genera numerosos trayectos hacia el centro, contaminación y mayores costos para las familias.

Ante esta dificultad, se plantea la redensificación: el aumento de la población en un área urbana específica. La ciudad, que ha crecido hacia los extremos, ahora se proyecta hacia las alturas. Adicionalmente, se propone la construcción de vivienda de interés prioritario (VIP), para promover el equilibrio y la equidad territorial (Decreto 190 de 2004, art 1. ${ }^{\circ}$ ). En este punto surgen algunas preguntas: ¿Basta con trasladar la población desde la periferia hacia los centros para solucionar los problemas de movilidad, acceso a servicios, condiciones de pobreza y desigualdad? ¿Cuáles pueden ser las implicaciones culturales de integrar diferentes sectores sociales construyendo VIP en las zonas centrales?

Siguiendo la política de competitividad, a través de los proyectos de renovación se busca "atraer inversión privada para consolidar el centro de la ciudad de Bogotá como centro de la red regional de ciudades” (Decreto 190 de 2004, art. 8). Por este motivo, se promueve la recuperación residencial, cultural, turística, hospitalaria y universitaria. Todos estos cambios se evidencian en el territorio: antiguos locales han sido transformados en boutiques, lujosos restaurantes, numerosos hostales y hoteles; hay ahora una mayor cantidad de extranjeros y estudiantes que ocupan el centro y menos vendedores ambulantes. En la medida en que siga avanzando el proyecto, ¿la disminución de la inequidad social prometida por el POT se cumplirá? ¿Quiénes tendrán derecho a permanecer en el territorio? ¿Quiénes tienen la capacidad de invertir y de permanecer una vez se incremente el valor del suelo? Hay que reconocer que la política de competitividad también está generando un desplazamiento material y simbólico en el

recursos públicos invertidos en el proyecto San Victorino Centro Internacional de Comercio Mayorista (Contraloría de Bogotá 2012). 
centro de la ciudad 9 , que está fragmentando poco a poco las relaciones sociales tejidas por los habitantes que le han dado forma a este sector (Smith 2013).

Desde el 2004, comenzó la formulación del Plan Zonal del Centro, en la cual participaron organismos estatales, privados y extranjeros: el Fondo General de Cooperación de España (FGCE) ${ }^{10}$, el Banco Interamericano de Desarrollo (BID), la firma Consultora IDOM, el Fondo Fiduciario Italiano para la Herencia Cultural y el Desarrollo Sostenible (ICH), el Departamento Administrativo de Planeación Distrital, que pertenece a su vez a la Secretaría Distrital de Planeación, la ERU (BID 2006) y la Corporación de Universidades del Centro ${ }^{11}$. En el 2007, mediante el Decreto 492 (Secretaría General de la Alcaldía Mayor de Bogotá 2007a), se adoptó el Plan Zonal del Centro para la ciudad de Bogotá, en el cual se establecía la recuperación, el mejoramiento y el estímulo de la infraestructura inmobiliaria y de servicios para redensificar la zona. A través de los proyectos de renovación urbana y de la inversión pública, se buscó aplicar una política de competitividad que garantizara la inversión privada y posicionara al centro dentro de la red regional de ciudades. Esto se llevó a cabo por medio de programas territoriales urbanos, sociales, económicos e institucionales en Las Cruces y San Bernardo, San Victorino Regional, Calle 26 y Centro Tradicional, Mariscal Sucre, Teusaquillo y Soledad. Al observar la diferencia de actores que intervienen en la construcción del centro, la relación entre lo público y lo privado entra en tensión. Al respecto, Arteaga y Escallón (2012) plantean:

[...] si bien es cierto que las operaciones de renovación urbana han sido dirigidas o lideradas en gran parte por el sector público, es igualmente cierto que son propiciadas por presiones privadas sobre un suelo bien localizado, con alto valor inmobiliario y con un alto grado de deterioro. (23)

$9 \quad$ El desplazamiento material tiene varios componentes: el cierre de negocios tradicionales y la apertura de establecimientos para grupos de mayores ingresos; la presión inmobiliaria para la venta de predios; el hecho de que, ante la falta de recursos para el mantenimiento de viviendas, los antiguos habitantes se trasladen a otros sectores; y la expulsión de otros, debido a la implementación de obras de renovación. El desplazamiento simbólico se caracteriza por una percepción de exclusión social entre los antiguos habitantes, la falta de información sobre el futuro de su vivienda y el abandono de ciertos barrios por parte de la policía y de las empresas recolectoras de basura, que tiene el fin de devaluar la zona (Smith 2013). portal/site/mineco/menuitem.985155cef7bd1f74bec94510026041a0/?vgnextoid=add92b661425b 310VgnVCM1000002006140aRCRD.

11 Consultar página de la Universidad del Rosario sobre la Corporación de Universidades del Centro. http://www.urosario.edu.co/Ciencia-Politica-y-Gobierno/GestionDesarrolloUrbanos Ekistica/ur/Relacion-con-la-sociedad/Corporacion-de-Universidades-del-Centro/. 
En los años noventa se hablaba de regeneración urbana, una política enfocada en adaptar la estructura social y física anterior a las necesidades actuales. Sin embargo, las políticas en Colombia han actuado desde el principio de la renovación urbana de los setenta, optando por la demolición y reconstrucción de zonas obsoletas, una operación cuestionada por quebrar lazos sociales, beneficiar principalmente a operadores privados y romper con la morfología urbana anterior (Arteaga y Escallón 2012).

El Plan de Desarrollo 2012-2016 establece "la permanencia de los propietarios y habitantes originales o su vinculación voluntaria a proyectos asociativos, con una distribución equitativa de las cargas y los beneficios”, que incluye en los programas de renovación del centro la "vivienda de interés prioritario" (art. 6). Aquí hay un cambio de enfoque que pone en el centro al ser humano y se distancia del desplazamiento de la población. Es importante revisar a profundidad las estrategias de acción y el plan de trabajo de las instituciones encargadas de disminuir la segregación y el acceso a la vivienda, pues lo que está ocurriendo con los proyectos Progresa Fenicia, Ministerios, Proscenio y Estación Central es que se continúa con la línea de renovación urbana sin reconocer las estructuras físicas, sociales y económicas anteriores (Arteaga y Escallón 2012).

\section{El centro histórico deteriorado}

“Cambiar la ciudad para cambiar la sociedad” (Topalov 1990, 337) era el pensamiento dominante a principios del siglo XX en Europa y América del Norte, ante la situación que se vivía en las ciudades industriales. En esta época se construyen las primeras políticas de ordenamiento urbano, de gran influencia para la planeación de nuestras ciudades. Esto no resulta extraño si recordamos que, de acuerdo con Schneier (1990), las ciudades en América Latina se construyen como réplicas del mundo europeo: "la ciudad fue el instrumento de un proyecto colonial asentado sobre bases jurídicas y teológicas” (358) que garantizó el control territorial. Este proyecto adquiere connotaciones diversas en cada territorio, sin embargo, la explosión urbana, la economía informal y la segregación urbana mencionadas por Schneier son comunes a todas las ciudades latinoamericanas.

El barrio Las Aguas, donde se ubica la Manzana 5, hace parte del centro histórico de Bogotá. Esta zona se ha convertido en un espacio estratégico:

[allí] se congregan las manifestaciones culturales nacionales, representadas en las actividades tradicionales de la población residente 
principalmente, [es un lugar] dotado de los equipamientos culturales, comunales y administrativos, y con espacios públicos simbólicos en la historia de la ciudad, del país y de la nación. (“Objetivos y estrategias”)

Según un informe preparado para el Banco Interamericano de Desarrollo (BID), la recuperación de los centros históricos en América Latina se justifica de la siguiente manera:

En los países de ALC [América Latina y el Caribe], gran parte de la riqueza cultural se concentra en los centros históricos de las ciudades. Sin embargo, y casi sin excepción, la mayoría de estos centros han sido afectados negativamente por procesos de deterioro que ponen en riesgo la preservación del legado histórico cultural que dichos centros albergan. Así, las ciudades comienzan a perder un recurso valioso que, preservado y explotado adecuadamente, puede contribuir a la calidad de vida de sus ciudadanos. (Cuenín 2009, 1; énfasis míos)

Esta perspectiva posiciona a la cultura como promotora de desarrollo económico y social. Al no especificar las características del legado cultural e histórico, puede pensarse en los centros de gobierno, en los museos y en aquellos espacios que albergan la versión oficial de la historia. Esta definición desconoce la dinámica cultural del centro histórico que se observa en las calles, en los muros, y la que es narrada por sus habitantes en la cotidianidad. El deterioro del patrimonio también se instrumentaliza, para promover proyectos de renovación y para el beneficio de inmobiliarias y de inversionistas privados que compran barato y venden caro una vez se valoriza la zona. El deterioro se puede entender como un recurso político para garantizar la apropiación y la renovación de territorios que, como bien se indica, son valiosos en la medida en que pueden ser explotados para generar rentabilidad. Y en este orden, la preservación patrimonial $^{12}$ se convierte en un “instrumento más para el desarrollo de las ciudades”, un salvavidas para mitigar los innumerables problemas del centro histórico: “inseguridad, desempleo, problemas ambientales, uso irracional de espacio público, falta de dinamismo económico, etc.” (Cuenín 2009, 13).

Por ningún lado se habla de las causas del deterioro, que es una problemática social desligada de su referente histórico y político. ¿Por qué los centros

12 Entre los temas principales se destaca la revitalización de áreas centrales patrimoniales $\mathrm{y}$, en forma creciente, el turismo cultural: en los últimos 10 años el Banco invirtió US\$630 millones para rehabilitar áreas urbanas centrales en América Latina (46 operaciones), y US\$102 millones en turismo cultural (23 operaciones) (Cuenín 2009). 
históricos son depositarios de dichas problemáticas? Según un estudio de la Cámara de Comercio de Bogotá (2005), la principal justificación para recuperar los centros históricos es el deterioro, una característica común de los centros de los países en desarrollo. Esta mirada despierta varias críticas: en primer lugar, presentar el deterioro como verdad incuestionable impide analizar causas, facetas, actores e implicaciones políticas; en segundo lugar, afirmar que es una característica común impide divisar las diferencias de cada contexto; y, finalmente, no se habla de la falta de inversión en la zona, la segregación urbana, la compra y el deterioro programado de los predios, la formación de diversos centros financieros en la ciudad, los usos del suelo y la distribución de la vivienda, así como del proyecto de convertir a Bogotá en una ciudad de servicios ${ }^{13}$. Montezuma (1999) advierte que la percepción de deterioro proviene principalmente de las clases altas, que se ven amenazadas por la presencia de clases populares en el centro y temen su consecuente pérdida de control sobre dicho territorio. El autor sugiere dejar de pensar el estado actual del sector en términos de deterioro y comprender, en su lugar, la evolución del centro en relación con otros centros de la ciudad, con políticas económicas particulares y con la problemática de la movilidad.

Esta racionalización del espacio es el escenario perfecto para la renovación, que puede ser estudiada desde la diferenciación y el rechazo (De Certeau 2008). La diferenciación es una clasificación funcional de los espacios: cortes, retazos, ajustes. El rechazo corresponde a lo que no pasa el filtro anterior, a lo que conforma el grupo de lo eliminable. Los desechos deben ser intervenidos, todo debe quedar perfectamente articulado en la memoria. La articulación se vale del progreso para crear opuestos; no se habla de enfermedad, se busca salud, seguridad y demás valores positivos.

La renovación urbana se caracteriza más por sus políticas de competitividad que por plantear políticas sociales fuertes. Es una respuesta política a la violencia que apela a la seguridad y promueve otras zonas del miedo, de manera que desplaza las problemáticas sociales ${ }^{14}$. Esto es lo que le da la característica de estrategia kitsch, un ideal estético del que habla Kundera y que nos recuerda aquello que ha sido invisibilizado ${ }^{15}$. Al privilegiar el embellecimiento

13 Véanse "Bogotá, la capital" (2012), Rico (2013) y Comisión Regional de Competitividad (2010).

14 "Los barrios San Bernardo y Las Cruces [...] recibieron gran parte de la gente que fue desplazada al eliminarse el sector del Cartucho, que estaba ubicado en el actual parque Tercer Milenio" (Cuenín 2009, 24). elimina de su punto de vista todo lo que en la existencia humana es esencialmente inaceptable" (Kundera 2002, 254). 
por encima de las consecuencias sociales (Góngora y Suárez 2008; Suárez 2010), ¿adónde van los sujetos desplazados? y ¿en qué lugar quedan confinadas las problemáticas existentes?

El Banco Interamericano de Desarrollo ha jugado un rol central en la recuperación de los centros históricos que inició en 1994, con la revitalización del centro histórico de Quito ${ }^{16}$. Bogotá y Cartagena hacen parte de la segunda generación de programas de revitalización. Los primeros se reformularon con el fin de dar sostenibilidad a los procesos, lo que implica mantener los centros históricos en actividad, asegurando el trabajo, la vivienda y el consumo. Adicionalmente, deben evitar que los logros alcanzados hasta el momento con otros proyectos de renovación se vean amenazados.

Sin duda, el panorama del centro histórico debe estudiarse en relación con los barrios cercanos. En el mapa se identifican límites claros entre un barrio y otro, entre una localidad y otra, pero al salir de ese esquema y entrar en el territorio surgen múltiples articulaciones. Sobre todo, es interesante revisar esta dinámica cuando se estudian las luchas territoriales.

\section{Trabajar sobre las ruinas}

Gracias a la casa, un gran número de nuestros recuerdos tienen albergue, y si esa casa se complica un poco, si tiene sótano y guardilla, rincones y corredores, nuestros recuerdos hallan refugios cada vez más caracterizados. Volvemos a ellos toda la vida en nuestros ensueños.

(Bachelard 2013, 38)

Cuando logré contactar a la familia Torres, en julio del 2013, su casa era la última que quedaba en la manzana. Conversé con José durante un buen rato en la panadería Doña Blanca, ubicada sobre la carrera $1{ }^{a}$. Al terminar el café nos dirigimos a su casa y allí estuvimos en compañía de su mamá, una mujer de la tercera edad. Nos sentamos alrededor de una mesa y el techo destapado de esa zona de la casa permitía ver la última pared, o el rastro de pared que quedaba del edificio donde vivió Jairo Aníbal Niño, inmueble que había sido declarado patrimonio.

\footnotetext{
16 "En los últimos diez años el banco ha invertido más de US\$630 millones en la revitalización de áreas centrales (46 operaciones) y más de US\$100 millones en proyectos asociados a turismo cultural (23 operaciones)" (Cuenín 2009, 2).
} 
Una máquina puede demoler en un segundo cuarenta años de recuerdos, y así fue en este caso. El 9 de agosto, José y su mamá salieron con todas sus cosas de la que había sido su casa durante más de cuarenta años, donde crecieron los hijos de la familia. Una semana después me enteré de la demolición. Aquella tarde de agosto, llamé a José Torres para acordar el día de la grabación en su casa y lo primero que me dijo es que ya no estaba viviendo allá, que ahora se encontraba en Mosquera. "Hace una semana salí de allá. De vez en cuando voy a hacer vueltas al centro. Para mí es muy doloroso, para qué quiero ir a ver un hueco” (J. Torres, comunicación personal). Al escuchar esas palabras alcancé a sentir el impacto de la casa derrumbada, no importaba que fuera a través de un celular. Me pesó enormemente no tener un registro visual de la última casa que quedaba y entendí la importancia de la descripción al momento de narrar lo que ya no es visible. Están las voces, los recuerdos, los silencios y la posibilidad de narrar sobre los escombros en una ciudad donde la memoria es cada vez más difusa. Aquí siguen construyendo sobre las ruinas, seguimos avanzando sobre el olvido.

Cuando me enteré de la noticia, a las dos de la tarde, sentí la necesidad de salir corriendo hasta la calle 20 con 1 . $^{\text {a }}$ para tomar una foto del lugar; necesitaba ver lo que había quedado. Desde el norte de la ciudad emprendí camino al centro. Al llegar a la estación de Las Aguas, salí por la calle del Centro Colombo Americano y subí por el Eje Ambiental, donde observé un paisaje de letreros, cemento, rastros de paredes, escombros y la máquina con la que derrumbaron la última casa. Esa vez, con cada paso, confirmaba la destrucción de un lugar. A través de la reja, divisé un espacio privado e inaccesible. Me acerqué y pregunté al celador si era posible entrar para tomar algunas fotos; me respondió que no. Le conté que era para un trabajo de la universidad e insistí en hablar con alguien más. En ese momento salía uno de los arquitectos encargados de la obra y el celador me hizo el favor de preguntarle. Al parecer, la respuesta fue también un no rotundo, pues de lejos el celador hizo una señal negativa con la mano y luego el arquitecto salió en su carro. Cuando regresó, afirmó que nadie podía entrar y yo aproveché para preguntar si ya iban a empezar a construir. "Primero tienen que hacer el edificio modelo y de forma seguida inicia la obra” (comunicación personal). El espacio está destinado para levantar tres torres; no se construirá un centro cultural. Esto confirma que el proyecto inicial pensado para el acceso público, aquel que implicó el desplazamiento de las familias, terminará beneficiando a agentes privados. Camino por el Eje Ambiental esperando encontrar la puerta de la casa; allí está, en pie, la fachada. La puerta azul y las marcas sobre la pared son lo único que queda (figura 1). Carteles indescifrables, firmas anónimas y el nombre de una santa, santa Antonia, que en algún momento sirvió para recordarle al transeúnte que allí podía encontrar una tienda de barrio. 
Figura 1. Fachada de la casa donde vivía la familia Torres

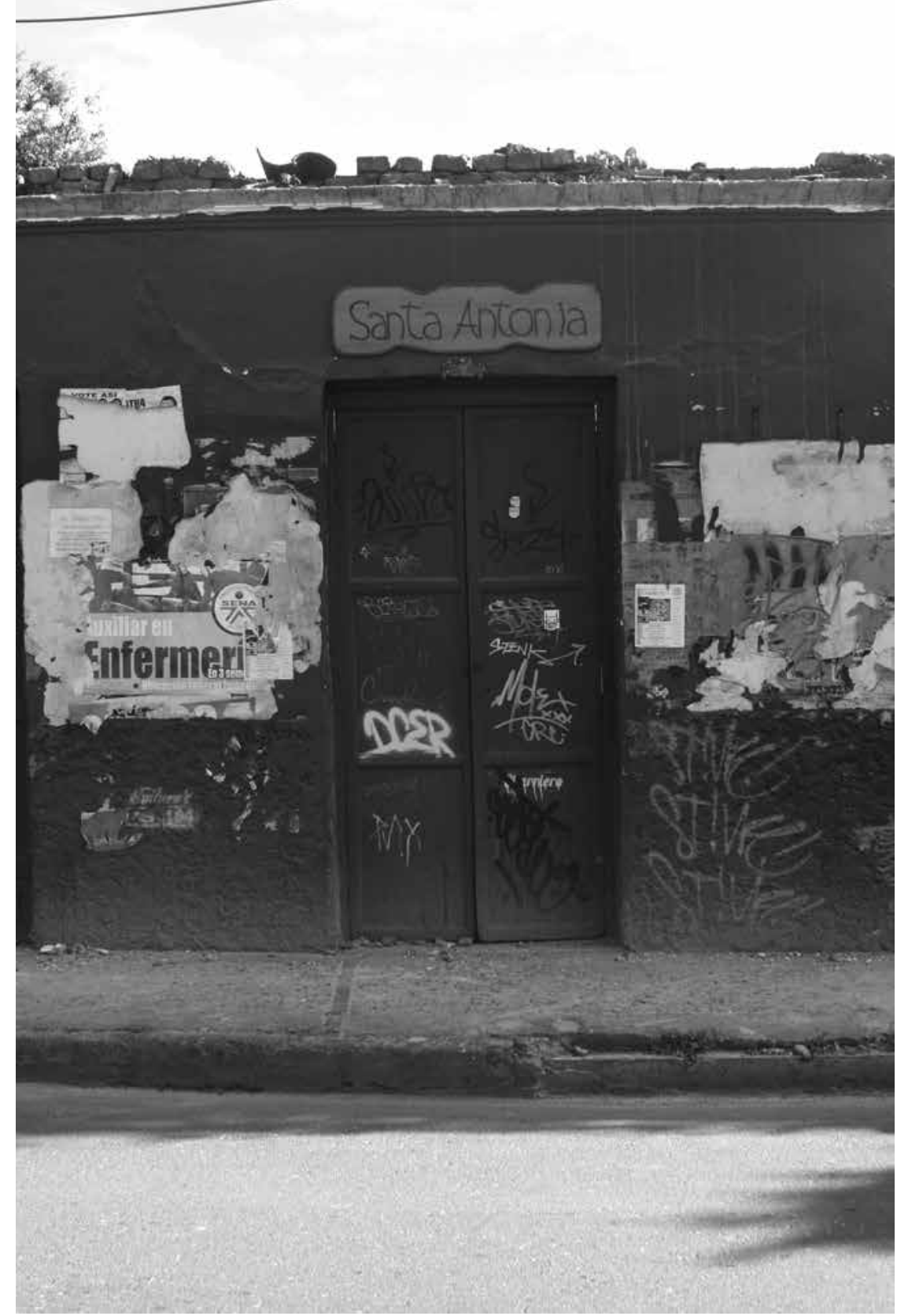

Fuente: Fotografía de la autora. 
Figura 2. Fachada de la casa donde vivía la familia Arango

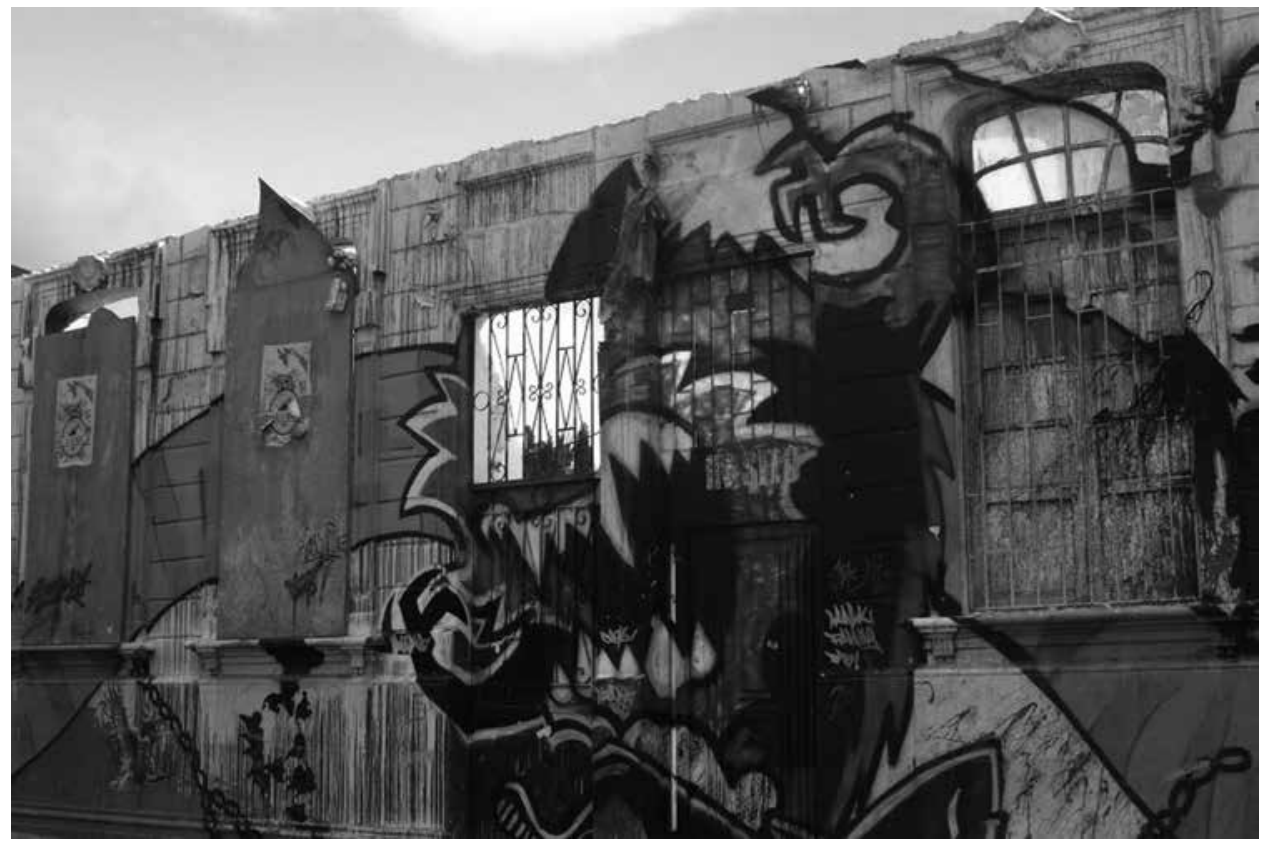

Fuente: Fotografía de la autora.

También fue posible registrar la fachada de la casa que pertenecía a la familia Arango (figura 2). Trabajar sobre las ruinas es leer los mensajes que han quedado en los muros, esos gritos de colores representados por grafitis.

En el costado del frente había una señora en la puerta. Ella cuenta que hace poco sacaron a la última familia. "El viernes de la semana pasada, tan pronto se fueron, llegó la máquina a demoler la casa. Seguramente temían que en algún momento regresaran y ocuparan nuevamente el lugar”. Nos cuenta que ese mismo año demolieron la casa de Camilo Arango y que ella estuvo como testigo. Camilo se aferró a la puerta, atrás estaba la máquina derrumbando la casa y fue necesario que la detuvieran porque él no se movía. Le dijo a la señora Teresa que se quedaría allí, y que si la máquina lo aplastaba ella podría dar cuenta de lo ocurrido. Ahora sí van a empezar a construir, continúa, pero hay muchas demandas de por medio que no se han resuelto.

Actualmente, donde ella está viviendo se adelanta el proyecto Triángulo de Fenicia, gestionado por la Universidad de los Andes. En el año 2008, siguiendo los lineamientos del POT, la universidad propuso el proyecto de renovación para las manzanas que se encuentran entre la avenida Circunvalar, el Eje Ambiental 
y la carrera 3. ${ }^{a}$. Luego de incluir a la comunidad en el proyecto, en el 2010, la institución presentó el Programa Progresa Fenicia, cuya misión es revitalizar el sector construyendo viviendas, centros comerciales, hoteles y espacio público. ¿Quiénes serán los beneficiarios de este proyecto? ¿Realmente incluyen a la población residente? Estas son algunas de las preguntas que han movilizado a los habitantes del sector.

¿Qué nos dice el relato de las ruinas sobre la forma de relacionarnos con la memoria, la historia y el paso del tiempo? ¿Hasta qué punto esa urgencia demoledora refleja nuestros deseos modernizadores, de estatus y de consumo? Para Gómez y Serna (2010), la configuración histórica de Bogotá se ha caracterizado por el distanciamiento y el confinamiento, producto de la expansión urbana, la segregación física y social, y la abismal brecha entre clases sociales. Así, se configura una memoria que no distingue claramente entre lo antiguo y lo nuevo. En esta ciudad, "el exceso de necesidades o de funciones incidió poderosamente en que los lugares más que antiguos solo fueran viejos y [en] que los más recientes, aun los más inéditos o innovadores, recalcaran prontamente en una vejez precoz” (140). Esta mirada permite ampliar la perspectiva sobre las ruinas, específicamente de los centros históricos, que son espacios más propensos a decaer, debido a la exacerbación de necesidades y de funcionalidad. Como lo advierten los autores, un espacio en ruinas es mucho más que "falta de identidad y de sentido de pertenencia para con la ciudad” (140).

\section{Desplazamiento urbano}

En un contexto de competencia mundial, el marketing urbano se convierte en un proyecto político que transforma la ciudad en una marca. Necesitamos embellecernos, renovarnos, ser positivos, amar a Bogotá ${ }^{17}$, construir una linda fachada y desplazar la pobreza. La mejor forma de lograrlo es borrando la memoria. Esta vez, al desplazamiento causado por el conflicto armado se le une el desplazamiento producto de la renovación urbana.

Es importante mencionar que la categoría de desplazamiento urbano emerge en las conversaciones y entrevistas con los residentes afectados. Ellos se autodenominan desplazados y nombran el evento como un desplazamiento a manos 
del estado. Este desplazamiento se realiza legalmente y no cumple con un proceso de participación: “o vende o lo expropiamos” es la frase más utilizada al hablar de la negociación con la ERU.

Si bien el proyecto de la Manzana 5 comenzó en el 2006 y al día de hoy se han cerrado la mayoría de negociaciones, es necesario conocer que, debido a las irregularidades en el proceso realizado por la ERU, los propietarios de los predios expropiados interpusieron acciones judiciales mediante las que solicitaron el cumplimiento de la ley, el restablecimiento de derechos y una reparación por los daños causados por parte de la entidad del estado (Contraloría de Bogotá 2011a). Más allá de la denuncia, el proceso de expulsión y las irregularidades en la ejecución de los proyectos de renovación son procedimientos que dicen algo sobre el paradigma con el cual se construye la ciudad y sobre la relación entre el estado y los ciudadanos.

Jairo Castrillón tenía su sastrería desde hace cuarenta años en el lote elegido para la construcción del centro cultural. A partir del primer comunicado, inició una disputa con la ERU. Jairo menciona que se realizaron diferentes reuniones con la institución, en las que se difundió información sobre los planes de renovación, la transformación del centro y los beneficios de participar en el proyecto. Nunca se abrió realmente un espacio de debate y de negociación que contemplara las memorias, los intereses de los residentes o propietarios. En varias ocasiones nombra a una funcionaria de la ERU que en tono amenazante decía: "si no venden los expropiamos” (J. Castrillón, comunicación personal).

A pesar de ser un lote poco habitado, Jairo señala que este espacio tenía una dinámica comercial propia y que no es cierto que estuviera deteriorado. Señala que el deterioro se generó como consecuencia de la compra y la desocupación de lotes. "Yo vendí, me vi obligado a vender” (J. Castrillón, comunicación personal), dice, y hace énfasis en que la transformación generada por la desocupación era perjudicial para la imagen de su negocio textil. Con esto se refiere a la ocupación de lotes por parte de habitantes de la calle, los malos olores, el descuido, etc. Si bien no hubo un proceso sólido de organización (eran pocos los propietarios y no estaban tan arraigados), destaca que el mecanismo de intimidación institucional logró finalmente desplazar a los habitantes.

En cuanto al efecto que tiene el desplazamiento en las vidas personales, cabe destacar que estamos hablando de personas mayores o de la tercera edad, a las cuales el despojo de sus bienes les ha causado problemas de salud. Algunos vecinos y residentes cuentan que, luego de haber sido desplazado de su casa, el poeta Jairo Aníbal Niño se deprimió mucho y al poco tiempo murió. No en vano escribe el documento titulado “Allí crecieron los hijos” (Silva 2012). 
La familia Torres fue la última en salir, luego de siete años de resistencia y de tomar bajo posesión su propia casa. Subrayan que en ningún momento se abrió un espacio de negociación y que, por la vía legal, la ERU está desplazando a los habitantes del centro. Durante la conversación, la mamá de José Torres le otorgó un lugar principal a la familia, se retiró para traer fotografías de sus familiares y del esposo que había fallecido recientemente. Para ella fue importante narrar quién era, de dónde venía, dar cuenta de su familia que vivió cincuenta años en esa casa que ahora debían dejar, por un proyecto avalado por el estado que no se ha llevado a cabo. Allí también se ubicaba una tienda que era fuente de ingresos para la familia. Se trata, entonces, de recuperar la memoria de un lugar, los rostros de un espacio en proceso de demolición, las familias que allí vivían. Este es un acto que contradice la construcción del territorio por los planes de ordenamiento que, al privilegiar el interés general sobre el particular, pasan por alto dichas memorias.

Amelia y Saúl son los habitantes que no han recibido dinero por su terreno y en esta lucha llevan siete años ${ }^{18}$. Al igual que en los casos anteriores, hablamos del desplazamiento de su vivienda y de su actividad económica, pues ellos vivían de las ganancias que les dejaba el parqueadero. Luego de narrar la lucha jurídica que han adelantado y las irregularidades en el proceso, ante el silencio de las entidades del gobierno, a la señora Amelia no le queda otra cosa que decir: "Entonces, ¿a quién apelamos si esos son los padres de la justicia? ¿Pero de qué justicia hablamos? Se equivocaron de nombre” (A. Sanabria, comunicación personal). En este punto me permito transcribir un fragmento del discurso emitido por doña Amelia en la audiencia de la Comisión Primera de la Cámara de Representantes en el año 2010:

Entonces yo pregunto, si la Alcaldía Mayor es la jefe de Renovación Urbana, creo que no debe estar enterada de todos los atropellos que han cometido con nosotros, los desplazados de la Manzana 5, donde toda nuestra vida trabajamos para tener nuestro rancho y nuestro negocio, y llegó un momento en que Renovación Urbana, como una guerrilla, peor que la guerrilla, llegó y nos sacó sin ton ni son. Simplemente se van ustedes de aquí y listo. No entiendo cómo es posible que la Alcaldía Mayor de Bogotá, con los escritos - por ejemplo, la auditoría que le hizo la Contraloría-, y el Concejo no se habían dado cuenta de todos esos atropellos, cómo han pisoteado los derechos fundamentales, mejor dicho, es que no encuentro palabras para decir qué calidad de empresa es esa [...] 
En este problema llevamos prácticamente cinco años y lo poco que nos ofrecieron - a doscientos mil pesos el metro cuadrado en un sitio tan predilecto como ese- [...] no nos lo han pagado. Mire, estamos viviendo en el apartamento de mi hijo. Si no tuviéramos ese apartamento, donde él nos hospedó, entonces estaríamos viviendo debajo del puente, estaríamos viviendo como cualquier habitante de calle. Eso que lo haga una entidad del gobierno, por Dios, es increíble. Que lo hagan los ladrones, está bien, pero una entidad del gobierno, que porque tiene licencia, nos sacó, nos robó y de todo. No puede ser posible. (A. Sanabria, comunicación personal)

Las políticas y sus mecanismos burocráticos funcionan hasta cierto punto, por lo tanto, la situación es más compleja que la falta de información o la falta de participación y movilización de los habitantes. Se han dado luchas individuales -alguna relación deben tener con la fragmentación de la lucha social y las políticas de participación- no menos importantes que las grandes movilizaciones. Las luchas individuales realizadas por los habitantes de la Manzana 5 son contundentes en la medida en que agotan los mecanismos jurídicos a través de los cuales se puede dialogar con el gobierno. De esta forma, se convierten en interlocutores legítimos que reconocen el lenguaje jurídico y político utilizado para realizar reivindicaciones, pero tal y como ellos lo han expresado en las entrevistas, encuentran dificultades para recibir una respuesta a tiempo y el pago oportuno del dinero que les corresponde ${ }^{19}$.

Desde el 2006 al día de hoy, cabe resaltar el progreso que ha tenido la organización de los habitantes del centro. En el 2010 se convocó la Asamblea CívicoPopular de Sectores, Veredas y Barrios Afectados por el Plan Zonal del Centro, para la consolidación del Mandato Popular del Centro (Asamblea Cívico-Popular de Sectores, Veredas y Barrios Afectados por el Plan Centro 2010). Participaron las localidades de Santa Fe, La Candelaria, Los Mártires, Antonio Nariño y San Cristóbal, principalmente. Uno de sus objetivos era alcanzar una "real participación decisoria de los propietarios, poseedores y arrendatarios en los planes y proyectos de renovación urbana”. Aquí se plantean propuestas concretas para la reforma de políticas públicas que contemplan la compleja situación que se vive en el centro en términos de desplazamiento, pobreza, deterioro del patrimonio, condición de la red hospitalaria y expansión universitaria, entre otras. 
Destaco también la construcción de espacios de participación en los sectores afectados por los proyectos de renovación: el Comité Interlocal del Centro (Mesa de Unidad Territorial 2006), el Comité Cívico-Popular del Centro, la Asociación de Propietarios del Barrio San Bernardo, el Comité en Defensa del Centro ${ }^{20}$ y el Comité No Se Tomen Las Aguas ${ }^{21}$. La lucha se ha fortalecido a través de la organización de asambleas, de movilizaciones por las zonas afectadas, de difusión de información sobre planes de renovación y de la respectiva formación política de los integrantes: estudiantes, propietarios y demás habitantes del centro que se pueden ver afectados por el proyecto.

Esta es una invitación a complejizar lo político, la participación y las prácticas locales de organización y lucha territorial. Es importante comenzar a entender el contexto en el que se inscriben las políticas de renovación y su relación con diversos factores culturales. Cuando hablemos de desplazamiento urbano, pensemos en la necesidad de distinción que nos caracteriza, en la abismal brecha entre clases sociales, en el modelo de desarrollo que edifica nuestra vida diaria, en nuestra urgencia por renovar y desechar todo lo viejo y deteriorado, y en la búsqueda de un estatus social que nos aleje de ese otro extraño y peligroso, porque bajo esta lógica unos pueden ser ciudadanos mientras que otros - como los indigentes- no. Pensemos, entonces, que una forma de avalar el conjunto renovación-expulsión es negando las memorias y los procesos históricos que han formado el territorio. Para tejer continuidades históricas es necesario respetar y apoyar la transformación de los procesos locales, en lugar de imponer el cambio y la modernización por medio de la destrucción.

\section{Estrategias legítimas e ilegítimas de ordenamiento territorial}

Sobre los desalojos violentos que han ocurrido en el marco de la renovación del centro histórico de Bogotá, puedo destacar su aspecto legítimo e ilegítimo. Hay políticas que legitiman la adquisición de predios - véase el contexto de la renovación urbana-, pero también existen estrategias ilegítimas que desocupan los espacios. En principio, a los residentes les llega una comunicación de la ERU que

Véase https://www.facebook.com/pages/El-centro-no-se-vende/459418457470061?fref=ts. 
les anuncia que su predio está ubicado en una zona donde se desarrollará un proyecto de renovación. Diferentes investigaciones y debates demuestran que no se llevan a cabo procesos realmente consultivos ${ }^{22}$.

Como parte de los procesos no legítimos, encontramos la violencia cotidiana a la que se recurre para desocupar espacios y que puede ser forzada, pero también silenciosa y lenta. La forzada tiene que ver con diferentes tipos de amenazas que reciben los residentes. Los testimonios de los desplazados de la Manzana 5 permiten corroborar que la ERU llegaba por la noche con policías, para sacarlos de la casa. En este terreno no pudieron llevar a cabo esta acción, pero no es un caso extraño en otros barrios cercanos.

A. Sanabria: Pero nosotros nunca tuvimos participación, ¿no te digo que venían era de noche con la policía a sacar la gente y mandaban quitar la luz, el agua?

Entrevistadora: A sacarlos de ahí...

S. Suárez: Y el agua nunca la cortaron, ni la luz, porque mientras haya gente ahí... Ellos mismos decían (los funcionarios del Acueducto), “nosotros no podemos cortar estos servicios”. (Comunicación personal)

Las estrategias más silenciosas se evidencian en asuntos tan básicos como la construcción de un puente frente al lugar de residencia, los espacios en obra que generan inseguridad, la ausencia de lugares de recreación o el deterioro intencional de la zona. Estos son tan solo algunos ejemplos de la forma como los procesos de renovación van cambiando la dinámica del lugar, su actividad económica, su habitabilidad, y de cómo van forzando a los antiguos residentes, de una u otra forma, a trasladarse a otro espacio de la ciudad donde puedan tener mejores condiciones de vida (funcionario del Instituto Distrital de la Participación y Acción Comunal [IDPAC], comunicación personal2²3.

Hay otras acciones que se mueven entre lo legítimo y lo ilegítimo, como el avalúo realizado a los predios que, de acuerdo con los habitantes, no corresponde con el precio real de esos terrenos. También podemos hablar de la expropiación que termina convirtiéndose en expulsión al no generar un bien público, ya que se otorgan los terrenos a constructores particulares. De igual forma, la fragmentación de la resistencia o de la organización social se debe revisar con detenimiento, pues en lugar de optar por procesos incluyentes y participativos se

22 Véanse los documentos del Instituto de Estudios Urbanos (2011a) y el reportaje de Cable Noticias (2011). 
llevan a cabo negociaciones individuales y se compran poco a poco los predios para luego abandonarlos, y así justificar la renovación.

Finalmente, está la creación o la modificación de la ley. Para adquirir los predios de la Manzana 5, se creó en el 2006 el Decreto 240, "por el cual se declara la existencia de condiciones de urgencia por razones de utilidad pública e interés social para un proyecto de renovación urbana" (Secretaría General de la Alcaldía Mayor de Bogotá 2006b). Al observar que algunos predios no habían quedado cobijados, se modifica la anterior norma a través del Decreto 368 del 2006 (Secretaría General de la Alcaldía Mayor de Bogotá 2006a), de modo que se incluyen todos los inmuebles ubicados dentro del área de ejecución del proyecto y que serían objeto de expropiación.

Más adelante, con la Resolución 0184 del 2007 (Secretaría General de la Alcaldía Mayor de Bogotá 2007b), que corresponde a los bienes de interés cultural de la Manzana 5 y fue firmada por el secretario distrital de Planeación, se modificó la categoría de intervención de dos bienes de interés cultural. Estos pasaron de la categoría B, bajo la cual habían sido declarados bienes de conservación arquitectónica, a la categoría $\mathrm{C}$, que hace posible que sean reedificables.

Es importante recordar que aquí lo que se está poniendo en evidencia no es la resistencia de los habitantes del centro a la renovación y al desarrollo de la ciudad. De forma similar lo plantea Patrick Morales (2013) al hablar de la gentrificación de Cartagena:

Estos planes culturales no son maléficos, son planes que buscan desmarginalizar y eso suena a progreso. Pero lo que hacen en realidad es construir un entorno al cual no tiene acceso la población allí asentada. Además, lo habitual es no escuchar las demandas de estos pobladores que claman por otro tipo de servicios alternos que mejoren su calidad de vida: estoy hablando de centros de salud, parques, espacios públicos más grandes, colegios para la gente que está viviendo allí. El plan lo que hace es pensar en las necesidades de quienes van a asentarse allí: normalmente una clase media, media alta o intelectual, que han llamado "los nuevos exploradores bohemios".

La organización barrial se está manifestando en contra de las irregularidades en la ejecución de los proyectos, el desplazamiento de familias y trabajadores, la ventaja económica que se está sacando del legado cultural e histórico del centro, sin tener en cuenta a los residentes que allí se encuentran ubicados. En últimas, se levantan en contra de la especulación y la venta del territorio a las inmobiliarias, a las empresas extranjeras y a los agentes privados. 


\section{Conclusiones}

Espero que las anteriores líneas hayan permitido entender la importancia que tiene la mirada etnográfica al explorar los efectos de las prácticas de renovación en el tejido social, la memoria y la construcción del territorio. Igualmente, están pensadas para abrir la posibilidad de explorar con mayor detalle las lógicas burocráticas; en algunos casos la ley se sigue al pie de la letra, se modifica si es necesario, pero existe una brecha muy amplia entre la formulación del proyecto de ley y la ejecución de los proyectos por parte de los funcionarios del estado en los diferentes territorios.

Si atendemos al discurso utilizado en las políticas territoriales, en los planes de desarrollo y en aquellos documentos que, en nombre del bien común, buscan rescatar el valor de los centros históricos por medio de la conservación del patrimonio, el turismo y la renovación, se puede encontrar que a la población de bajos ingresos, su estilo de vida, sus costumbres y al territorio en el cual viven se les asignan las peores características humanas. Se usan para referirse a ellos palabras que definen aspectos negativos que deben ser erradicados: degradación, inseguridad, condiciones precarias de salubridad, entre otros juicios de valor emitidos sin considerar la percepción de los habitantes sobre sus propias vidas. Y si se trata de mejorar la calidad de vida, ¿cuáles son los servicios que realmente necesita la población más vulnerable?, ¿cómo se implementan las políticas para la conservación de viviendas en los centros históricos? Me pregunto si existe algún interés en simplificar los trámites burocráticos para que las personas con menos recursos puedan conservar en condiciones dignas sus viviendas y no se vean forzadas a vender.

Entender lo urbano como un proceso permite incluir en el análisis las disputas que se dan en el territorio a lo largo del tiempo. En el caso de la Manzana 5, en nombre de lo común se recurre a la expropiación, pero los cambios que se dan durante la ejecución terminan asignando gran parte del territorio y de las ganancias del proyecto a agentes privados, inmobiliarias, constructoras y a una universidad privada, con el proyecto City U.

Las contradicciones que se presentan en la ejecución de proyectos y políticas afectan la legitimidad de los procesos de renovación y de los funcionarios del gobierno. Desde 1989, con la Ley de Reforma Urbana, se hablaba de la defensa de lo público y el desarrollo de proyectos de renovación que beneficien a la comunidad, pero en el proceso se han encontrado innumerables casos que demuestran cómo el despojo de tierras privadas, adquiridas para obtener una utilidad pública, no favorece a los habitantes. También se hablaba en ese momento de 
proteger a los habitantes del territorio para que fueran ubicados en una zona cercana, pero lo que se ha encontrado en la presente investigación es a un grupo poblacional desplazado a zonas periféricas en nombre de la renovación y de lo público. Esta es una de las más complejas contradicciones: construir un proyecto para promover el desarrollo haciendo un uso instrumental de la historia, de la cultura y del patrimonio, con el fin de favorecer intereses económicos privados y a los grupos de élite que tienen la capacidad de disfrutar del territorio. De no ser así, ¿cómo se evidencia entonces el mejoramiento de la calidad de vida de los sectores más vulnerables?

Desde el 2006, con la ejecución del proyecto Manzana 5 se presentaron inconsistencias que la administración ha intentado remediar en proyectos posteriores, y así quedó establecido en el Plan de Desarrollo 2012-2016. Sin embargo, en proyectos actuales como el de Fenicia, Ministerios, Proscenio y Estación Central, se siguen presentando falencias en la inclusión de la población residente. La participación democrática instaurada en 1997 es un derecho que tampoco se ha cumplido en su totalidad. Los habitantes resaltan las limitaciones de su participación, ya sea por la ineficacia de los espacios abiertos por el gobierno o por los obstáculos burocráticos que encuentran al buscar el cumplimiento de sus derechos.

Es necesario seguir estudiando la evolución de la lucha territorial urbana, la formación política que los habitantes van adquiriendo a lo largo del tiempo y las enseñanzas que dejan a su paso anteriores movilizaciones urbanas. De igual forma, es urgente recurrir a una mirada interdisciplinar para entender las bases de nuestra cultura política que favorecen la exclusión, el desplazamiento y la implementación de estrategias de gestión que continúan deslegitimando el rol de lo público, la ejecución de políticas públicas y los planes de ordenamiento.

\section{Referencias}

\author{
Alcaldía Mayor de Bogotá, Secretaría de \\ Planeación Distrital. 2013. Bogotá se \\ concentra. POT Una ciudad bien pensada. \\ Bogotá: Secretaría de Planeación. \\ -. 2014. Nueva Cinemateca de Bogotá. Cen- \\ tro para el desarrollo de las artes visuales \\ y audiovisuales. Consultado el 20 de \\ mayo del 2014. http://idartes.gov.co.
}

Arteaga, Isabel y Clemencia Escallón. 2012. "Entre la renovación y el reciclaje de tejidos urbanos consolidados”. Hábitat y Sociedad 5: 57-75. Consultado el 5 de abril de 2013. http://acdc.sav.us.es.

\section{Asamblea Cívico-Popular de Sectores,} Veredas y Barrios Afectados por el Plan Centro. 2010. Mandato popular del centro. Bogotá: Universidad Autónoma. Consultado el 15 de junio de 2015. http:// www.scribd.com/doc/37602011/MandatoPopular-Del-Centro-Secuencia. 
Bachelard, Gastón. 2013. La poética del espacio. México D. F.: Fondo de Cultura Económica.

\section{Banco Interamericano de Desarrollo} (BID). 2006. Apoyo para la preparación del proyecto de revitalización del centro de Bogotá. Consultado el 20 de abril de 2013. http://idbdocs.iadb.org/wsdocs/ getdocument.aspx?docnum=658225.

"Bogotá, la capital del turismo de salud". 2012. El Nuevo Siglo, 2 de noviembre. Consultado el 15 de junio de 2015. http:// www.elnuevosiglo.com.co.

Cable Noticias. 2011. "Desplazamiento urbano. Manzana 5”. 29 de noviembre. Consultado el 15 de junio de 2015. http://www.youtube.com/ watch?v=kU5OTbVAzQ8.

Cámara de Comercio de Bogotá. 2005. Caracterización de las estrategias de gestión público-privadas para la recuperación de centros urbanos. Bogotá: Vicepresidencia de Gestión Cívica y Social; Centro Hábitat Urbano.

\section{Comisión Regional de Competitividad.} 2010. Plan Regional de Competitividad. Bogotá y Cundinamarca 2010-2019. Bogotá: Secretaría Técnica Comisión Regional de Competitividad.

Contraloría de Bogotá. 2011a. Documento dirigido a María Fernanda Campo, alcaldesa mayor de Bogotá. Firma Mario Solano Calderón, contralor de Bogotá. Consultado el 20 de abril de 2013. http:// www.contraloriabogota.gov.co.

—. 2011b. "Informe final de auditoría abreviada. Evaluar el avance en los proyectos de inversión de la empresa de renovación urbana: Manzana 5 (lotes 1 y 2), construcción Centro Cultural Español CCE y vivienda de apartamentos para el desarrollo social”. http://www.contralo riabogota.gov.co.

-. 2012. "Informe final de la visita fiscal". Dirección Sector Control Urbano.
Empresa de Renovación Urbana (ERU). Plan de Auditoría Distrital 2012. Consultado el 5 de mayo de 2013. http://eru. gov.co/docs/Informe\%20final\%2020123580-E\%20Oct\%2026-12.pdf.

Crehan, Kate. 2004. Gramsci, culturay antropología. Barcelona: Bellaterra.

Cuenín, Fernando. 2009. Patrimonio cultural y desarrollo socioeconómico: la recuperación de áreas centrales históricas. Washington: Banco Interamericano de Desarrollo (BID).

De Certeau, Michel. 2008. "Andar en la ciudad”. Bifurcaciones 7: 1-17. Consultado el 15 de enero del 2013. http://www. bifurcaciones.cl.

Empresa de Renovación Urbana (ERU). 1999. Acuerdo 33 de 1999. Bogotá. Consultado el 20 de mayo del 2013. http:// www.eru.gov.co/docs/acuerdo_33_ de_1999.pdf.

-. 2006. Proyecto Eje Ambiental Manzana 5 Las Aguas. Documento técnico de soporte. Concertación de normativa urbana según Decreto 1042 de 1987. Bogotá: Empresa de Renovación Urbana (ERU).

“España reembolsó \$381 millones a Bogotá por fallido proyecto de construcción”. 2013. El Espectador, 15 de marzo. Consultado el 20 de marzo del 2013. http://www.elespectador.com.

Foucault, Michel. 2006. "Clase del 1 de febrero de 1978”. En Seguridad, territorio, población, 109-138. Buenos Aires: Fondo de Cultura Económica.

García, Diva. 2008. “Ordenamiento territorial y descentralización: competencias, recursos y perspectivas”. Papel Político 13 (2): 473-489. Consultado el 20 de marzo del 2013. http://www.scielo.org.co/ pdf/papel/v13n2/v13n2a04.

Gómez, Diana y Adrián Serna. 2010. Cuando la historia es recuerdo y olvido. Un estudio sobre la memoria, el conflicto y la 
vida urbana en Bogotá. Bogotá: Instituto para la Pedagogía, la Paz y el Conflicto Urbano (Ipazud).

\section{Góngora, Andrés y Carlos José Suárez.} 2008. "Por una Bogotá sin mugre: violencia, vida y muerte en la cloaca urbana". Universitas Humanística 66: 107-138.

Gusmerotti, Lucrecia. 2011. “'La toma': usos, sentidos e historicidad de una forma de acción colectiva en un movimiento social". Ponencia presentada en el grupo de trabajo " 11 procesos de movilización y de demanda colectivas: estudios y modos de abordar 'lo político' en la vida social", $\mathrm{X}$ Congreso Argentino de Antropología Social. Buenos Aires, Argentina.

\section{Instituto de Estudios Urbanos (IEU).}

2011a. "La política de renovación urbana en el Plan de Ordenamiento Territorial de Bogotá”. Debate de Gobierno Urbano 7: 1-15.

—. 2011b. "Procesos de expropiación en renovación urbana”. Debate de Gobierno Urbano 9: 1-19.

Kundera, Milan. 2003. La insoportable levedad del ser. Barcelona: Tusquets.

Low, Setha. 1996. "The Anthropology of Cities: Imagining and Theorizing the City”. Annual Review of Anthropology 25: 383-409. Consultado el 15 de abril del 2013. https://services.brics.dk.

Lulle, Thierry. 2008. "Prácticas y representaciones espaciales de los habitantes del centro de Bogotá”. Centro-h 1: 67-77. Consultado el 5 de mayo del 2013. http://132.248.9.34/hevila/CentrohQui to/2008/no1/5.pdf.

Mayorga, Jennifer. 2012. "Limitaciones en la gestión de planes parciales en áreas de renovación urbana en la ciudad de Bogotá D. C”. Tesis de maestría, Pontificia Universidad Javeriana. Consultado el 3 de junio del 2013. http://repository. javeriana.edu.co.
Mejía Pavony, Germán. 2000. Los años del cambio. Historia urbana de Bogotá 18201910. 2. ${ }^{\text {a }}$ ed. Bogotá: Pontificia Universidad Javeriana.

Mesa de Unidad Territorial. 2006. “Comité Interlocal y la Mesa de Unidad Territorial”. Interlocal_plancentro, 20 de julio. Consultado el 15 de junio de 2015. http:// interlocalplancentro.blogspot.com.

Montezuma, Ricardo. 1999. La transformación del centro de Bogotá: entre especialización y popularización. Experiencias latinoamericanas. Barrio Taller 7. Consultado el 20 de abril del 2013. http:// barriotaller.org.co/publicaciones.htm.

Morales, Patrick. 2013. "El desalojo neoliberal. La gentrificación en Cartagena”. Revista Arcadia, 20 de febrero. Consultado el 21 de marzo del 2013. http://www. revistaarcadia.com.

Moreno, Lucila. 2011. "La política como acción y el lenguaje de los (des)acuerdos: un estudio etnográfico de un programa de construcción de viviendas sociales en la zona norte del Gran Buenos Aires”. Ponencia presentada en el grupo de trabajo "11 procesos de movilización y de demanda colectivas: estudios y modos de abordar 'lo político' en la vida social”, del X Congreso Argentino de Antropología Social. Buenos Aires, Argentina.

Muzzopappa, Eva y Carla Villalta. 2011. "Los documentos como campo. Reflexiones teórico-metodológicas sobre un enfoque etnográfico de archivos y documentos estatales”. Revista Colombiana de Antropología 47 (1): 13- 42.

"Objetivos y estrategias de la Operación Estratégica del Centro (Plan Centro)”. Consultado el 5 de junio de 2013. http:// www.eru.gov.co/docs/Objetivos_de_la_ operacion_estrategica_del_centro.doc.

Oszlak, Oscar y Guillermo O'Donnell. 1982. "Estado y políticas estatales en 
América Latina: hacia una estrategia de investigación”. Revista Venezolana de Desarrollo Administrativo 1 (enero): 75-105.

Pérez, Federico. 2010. "Laboratorios de reconstrucción urbana: hacia una antropología de la política urbana en Colombia”. Antípoda 10: 51-84.

Ramírez, María Clemencia. 2010. "La antropología de la política pública”. Antípoda 10: 13-17.

Raposo, Gabriela. 2009. "Narrativas de la imagen: memoria, relato y fotografía". Revista Chilena de Antropología Visual 13: 79-103. Consultado el 10 de abril del 2013. http://www.rchav.cl/imagenes13/ imprimir/raposo.pdf.

Rico Reyes, Guillermo. 2013. "Un proyecto que enfermará a Bogotá”. Desde Abajo, 24 de septiembre. Consultado el 15 de junio de 2014. http://www.desdeabajo. info.

Roseberry, William. 2000. "Hegemonía y el lenguaje de la contienda”. En Taller interactivo: prácticas y representaciones de la nación, el estado y la ciudadanía en Perú. Traducido por Pablo Sendón, s. p. Lima: Instituto de Estudios Peruanos.

—. 2007. "Hegemonía y el lenguaje de la controversia”. En Antropología del estado. Dominación y prácticas contestatarias en América Latina, 117-137. Cuaderno de futuro n. ${ }^{\circ} 23$. Informe sobre desarrollo humano. La Paz: INDH; PNUD.

\section{Salcedo, Andrés y Austin Zeiderman.} 2008. "Antropología y ciudad: hacia un análisis crítico e histórico”. Antípoda 7: 63-97.

Saldarriaga, Alberto. 2000. Bogotá siglo $X X$. Urbanismo, arquitectura y vida urbana. Bogotá: Departamento Administrativo de Planeación Distrital.

Schneier, Graciela. 1990. "América Latina: una historia urbana”. Revista Internacional de Ciencias Sociales XLII (3): 355-372.
Secretaría General de la Alcaldía Mayor de Bogotá D. C. 1989. Ley 9 de 1989. Ley de Reforma Urbana. Bogotá: Secretaría General de la Alcaldía Mayor de Bogotá. Consultado el 5 de junio del 2013. http:// www.alcaldiabogota.gov.co/sisjur/nor mas/Norma1.jsp?i=1175.

—. 1997. Ley Nacional 388 de 1997. Bogotá: Secretaría General de la Alcaldía Mayor de Bogotá. Consultado el 5 de junio del 2013. http://www.alcaldiabogota.gov.co/ sisjur/normas/Norma1.jsp?i=339.

—. 1998. Decreto 879 de 1998. Planes de Ordenamiento Territorial. Bogotá: Secretaría General de la Alcaldía Mayor de Bogotá. Consultado el 5 de junio del 2013. http://www.alcaldiabogota.gov.co/sisjur/ normas/Norma1.jsp?i=1369.

-. 2000. Decreto 619 de 2000. Plan de Ordenamiento Territorial para Santafé de Bogotá, Distrito Capital. Bogotá: Secretaría General de la Alcaldía Mayor de Bogotá. Consultado el 5 de junio del 2013. http://www.alcaldiabogota.gov.co/sisjur/ normas/Norma1.jsp?i=1369.

-. 2004. Decreto 190 de 2004. Compilación Plan de Ordenamiento Territorial. Bogotá: Secretaría General de la Alcaldía Mayor de Bogotá. Consultado el 5 de junio del 2013. http://www.alcaldia bogota.gov.co/sisjur/normas/Norma1. jsp?i=13935.

-. 2006a. Decreto 368 de 2006. Modificación Decreto 240. Consultado el 5 de junio del 2013. http://www.alcaldia bogota.gov.co/sisjur/normas/Norma1. jsp?i=21580.

-. 2006b. Decreto 240 de 2006. "Condiciones de urgencia por razones de utilidad pública e interés social. Manzana 5”. Consultado el 5 de junio del 2013. http:// www.alcaldiabogota.gov.co/sisjur/nor mas/Norma1.jsp?i=20520.

-. 2007a. Decreto 492 de 2007. Operación Estratégica del Centro de Bogotá. 
Consultado el 5 de junio del 2013. http:// www.alcaldiabogota.gov.co/sisjur/normas/Norma1.jsp?i=27312\#0.

—. 2007b. Resolución 0184 del 7 de marzo del 2007. "Correspondiente a los bienes de interés cultural. Manzana 5”. Bogotá: Secretaría Distrital de Planeación.

-. 2012. Acuerdo 489 de 2012. Plan de Desarrollo 2012-2016. Consultado el 5 de junio del 2013. http://www.alcaldia bogota.gov.co/sisjur/normas/Norma1. jsp?i=47766

Shore, Cris. 2010. "La antropología y el estudio de la política pública: reflexiones sobre la formulación de las políticas”. Antípoda 10: 21-49.

Silva, Sergio. 2012. "Los desplazados de la Manzana 5”. Consultado el 3 de mayo del 2013. http://extereoactualidad.blogspot. com/2012/03/los-desplazados-de-la-man zana-5.html.

Smith Manrique, Adrián. 2013. "Gentrificación de La Candelaria: reconfiguraciones de lugar de residencia y consumo de grupos de altos ingresos”. Cuadernos de Geografía 22 (2): 211-234. Consultado el 8 de marzo del 2014. http://www.redalyc. org/articulo.oa?id=281826970010.

Suárez, Carlos José. 2010. "Renovación urbana. ¿Una respuesta al pánico moral?”. Territorios 22: 111-124.

Topalov, Christian. 1990. "De la 'cuestión social' a los 'problemas urbanos': los reformadores y la población de las metrópolis a principios del siglo XX”. Revista Internacional de Ciencias Sociales XLII (3): 337-354.

Torres, Alfonso. 2006. "Organizaciones populares, construcción de identidad y acción política”. Revista Latinoamericana de Ciencias Sociales, Niñez y Juventud 4 (2): 1-23. Consultado el 15 de abril del 2013. http://www.scielo.org.co/pdf/rlcs/v4n2/ v4n2a07.pdf.

Urbina, Amparo de. 2012. "El centro histórico de Bogotá 'de puertas para adentro': ¿el deterioro del patrimonio al servicio de la gentrificación?”. Cuadernos de Vivienda y Urbanismo 5 (9): 46-69.

Vargas, Juan Camilo. 2011. "El laberinto de los convocados. Planeación urbana y participación ciudadana en torno al Plan Zonal Centro de Bogotá”. Tesis de pregrado, Universidad Externado de Colombia.

Vera Groisman, Lucía. 2011. “¿Negociaciones?: el caso de la ocupación del parque Indoamericano”. Ponencia presentada en el grupo de trabajo " 11 procesos de movilización y de demanda colectivas: estudios y modos de abordar 'lo político' en la vida social”, del X Congreso Argentino de Antropología Social. Buenos Aires, Argentina.

Wincour, Rosalía. 1996. Introducción a De las políticas a los barrios. Programas culturales y participación popular, 17-30. Buenos Aires: Miño y Dávila Editores; Flacso. 